\title{
No Association between the CCR5432 Polymorphism and Sporadic Esophageal Cancer in Punjab, North-West India
}

\author{
Vasudha Sambyal ${ }^{1}$, Mridu Manjari ${ }^{2}$, Meena Sudan ${ }^{3}$, Manjit Singh Uppal ${ }^{4}$, Neeti \\ Rajan Singh $^{4}$, Harpreet Singh ${ }^{5}$, Kamlesh Guleria ${ }^{1 *}$
}

\begin{abstract}
Background: Chemokines and their receptors influence carcinogenesis and cysteine-cysteine chemokine receptor 5 (CCR5) directs spread of cancer to other tissues. A 32 base pair deletion in the coding region of CCR5 that might alter the expression or function of the protein has been implicated in a variety of immune-mediated diseases. The action of antiviral drugs being proposed as adjuvant therapy in cancer is dependent on CCR5 wild type status. In the present study, distribution of CCR5432 polymorphism was assessed in North Indian esophageal cancer patients to explore the potential of using chemokine receptors antagonists as adjuvant therapy. Materials and Methods: DNA samples of 175 sporadic esophageal cancer patients (69 males and 106 females) and 175 unrelated healthy control individuals (69 males and 106 females) were screened for the CCR5432 polymorphism by direct polymerase chain reaction (PCR). Results: The frequencies of wild type homozygous (CCR5/CCR5), heterozygous (CCR5/432) and homozygous mutant (432/432) genotypes were 96.0 vs 97.72\%, 4.0 vs $1.71 \%$ and 0 vs $0.57 \%$ in patients and controls respectively. There was no difference in the genotype and allele frequencies of $C C R 5 \triangle 32$ polymorphism in esophageal cancer patients and control group. Conclusions: The CCR5 32 polymorphism is not associated with esophageal cancer in North Indians. As the majority of patients express the wild type allele, there is potential of using antiviral drug therapy as adjuvant therapy.
\end{abstract}

Keywords: Chemokine - esophageal cancer - CCR5 332

Asian Pac J Cancer Prev, 16 (10), 4291-4295

\section{Introduction}

Tumor growth and metastatic dissemination develop through a complex molecular dysregulation involving cell migration, invasion, resistance to apoptosis, and immune escape mechanisms. Human and murine epithelial cancers contain a leukocyte infiltrate (Balkwill and Mantovani, 2001; Mantovani et al., 2002) and express a complex network of cytokines and chemokines (Wilson and Balkwill, 2002). Chemokines bind to cell surface receptors that belong to the G-protein-coupled receptor (GPCR) family, controlling diverse biological and pathological processes from immunosurveillance, inflammation, and cancer. Evaluation of different tumor types demonstrated that chemokines and their receptors might play roles in cancer cell growth and metastasis (Muller et al., 2001; Arya et al., 2003). Cysteine-cysteine chemokine receptor 5 (CCR5) is a chemokine belonging to the super family of the seven-transmembrane-G-protein coupled receptors. CCR5 is located on $3 \mathrm{p} 21.31$, comprising of three exons and encodes a 352 amino acid protein which is a member of $\beta$-chemokine receptors family of integral membrane proteins. The CCR5 432 arises from a $32 \mathrm{bp}$ deletion causing a frameshift at amino acid 185 which results in protein truncation. In animal studies, it has been suggested that $C C R 5$ and its ligands play a role in the pathogenesis and progression of vascular disease (Veillard et al., 2004; Potteaux et al., 2006; Zernecke et al., 2006). The potential role of $\Delta 32$ allele in pathogenesis of cancer has been evaluated with conflicting results in various gastrointestinal tract (GIT) cancers including pancreatic cancer (Duell et al., 2006), gall bladder cancer (Srivastava et al., 2008), oral cancer (Weng et al., 2010; Tanyel et al., 2013) and gastric cancer (Gawron et al., 2011). Apart from GIT cancers, the association of CCR5 $\triangle 32$ has also been evaluated in other cancers like skin cancer and bladder cancer (Zafiropoulos et al., 2004), cervical cancer (Zheng et al., 2006), osteosarcoma (von Luettichau et al., 2008), breast cancer (Manes et al., 2003; Zafiropoulos et al., 2004; Degerli et al., 2005; Aoki et al., 2009; Guleria et al., 2012; Eskandari-Nasab et al., 2014) and prostate cancer (Balistreri et al., 2009).

Intermediate and strong expression of CCR 5 has been reported in colorectal cancer (Erreni et al., 2009), melanoma (Seidl et al., 2007), hepatoma (Sutton et al., 2007), Hodgkin lymphoma (Aldinucci et al., 2008), oral (Chuang et al., 2009) and prostate cancer (Zhang et al., 2010). Positive serum CCR5 expression has also 
Vasudha Sambyal et al

been associated with a poor prognosis in gastric cancer (Sugasawa et al., 2008). But there is no published data on CCR5 32 in esophageal cancer.

CCR 5 genotyping has been described as a new diagnostic and prognostic strategy for therapy optimization (McDermott et al., 2010). Antiviral drugs are being proposed as adjuvant therapy for cancer (VelascoVelazquez et al., 2012). As these drugs are dependent for their action on wild type CCR5 forming functional protein, the present study was an attempt to determine the distribution of CCR5 432 deletion in esophageal cancer patients. Identification of $C C R 5$ and/or CCR5 ligand genes variants and their therapeutic response could allow physicians to tailor preventive therapies for patients. To the best of our knowledge, the present study is the first on distribution of the CCR5 432 in esophageal cancer patients from Punjab, a state in North West India.

\section{Materials and Methods}

\section{Study design and collection of samples}

In total, 175 clinically confirmed sporadic esophageal cancer patients were selected from Sri Guru Ram Das Institute of Medical Sciences and Research, Vallah, Sri Amritsar, Punjab. Patients who had received chemotherapy, radiotherapy or blood transfusion before surgery or had prior history of any cancer were excluded from the study. For each subject, a detailed personal history including age, habits, habitat, family history of cancer or any other disease and clinical details was collected in a pre-tested structured questionnaire. After informed consent, $5 \mathrm{ml}$ peripheral venous blood sample from 175 esophageal cancer patients and 175 age and gender matched unrelated healthy control individuals was collected. Control subjects were randomly selected from Amritsar city and villages adjoin Amritsar city. Individual who had family history of any type of cancer or any other chronic disease or on regular medications were not included in the control group. This study was carried out in accordance with the Declaration of Helsinki after approval by the ethics committee of Guru Nanak Dev University, Amritsar, Punjab, India.

\section{DNA extraction and CCR5 332 genotyping}

The genomic DNA was extracted from EDTA anticoagulated whole blood using standard phenol chloroform method (Adeli and Ogbonna, 1990). CCR5 432 (rs333) genotyping was performed by polymerase chain reaction (PCR) amplification of genomic DNA using previously published primer sequences (Apostolakis et al., 2005). A segment of $320 \mathrm{bp}$ of the CCR5 covering the site of deletion was amplified by PCR from the genomic DNA of the subjects. The PCR reaction was set in $10 \mu 1$ reaction volume containing 50ng DNA, 1X Taq buffer with $1.5 \mathrm{mM} \mathrm{MgCl} 2,0.3 \mu \mathrm{l} \mathrm{dNTPs}$ mixture (Bangalore GeNei), 6 picomole of each primer (Sigma, St. Louis, MO, USA), 0.5 U Taq DNA Polymerase (Bangalore GeNei). The PCR conditions were initial denaturation at $95^{\circ} \mathrm{C}$ for 5 minutes followed by 35 cycles with denaturation at $95^{\circ} \mathrm{C}$ for $45 \mathrm{~s}$, annealing at $59^{\circ} \mathrm{C}$ for $30 \mathrm{~s}$ and extension at $72^{\circ} \mathrm{C}$ for $45 \mathrm{~s}$, and final extension at $72^{\circ} \mathrm{C}$ for $10 \mathrm{~min}$ in a Mastercycler gradient, (Eppendorf, Germany). A negative control without template DNA was included in each reaction. PCR products were analyzed on ultraviolet transilluminated $2.3 \%$ ethidium bromide stained agarose gel. A band of 320bp indicated wild type homozygous (CCR5/CCR5) and two bands of 320bp and 288bp indicated heterozygous (CCR5/A32) genotype (Figure 1). Genotyping was performed without knowledge of case/control status. The validity of PCR based assay was proven by sequencing of different genotypes (Figure 2).

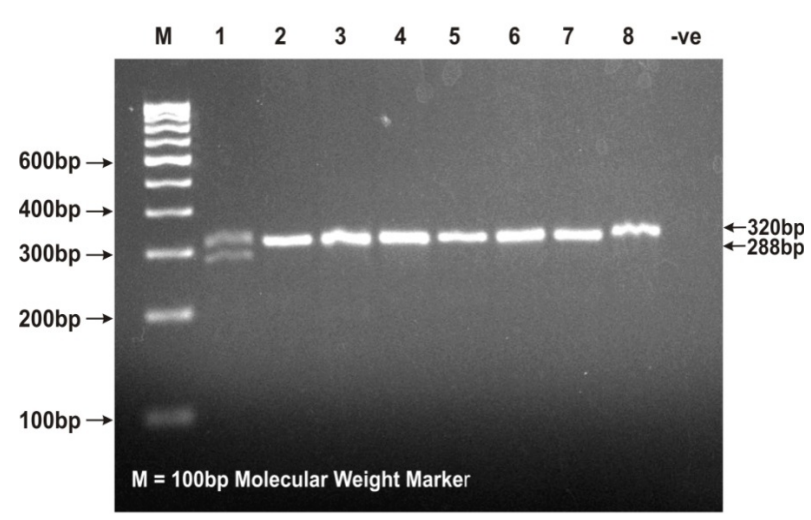

Figure 1. Gel Photograph Showing CCR5 Genotypes. Lane 1: heterozygous genotype (CCR5/ $\Delta 32)$, Lane 2-8: wildtype homozygous genotype (CCR5/CCR5), -ve: negative control

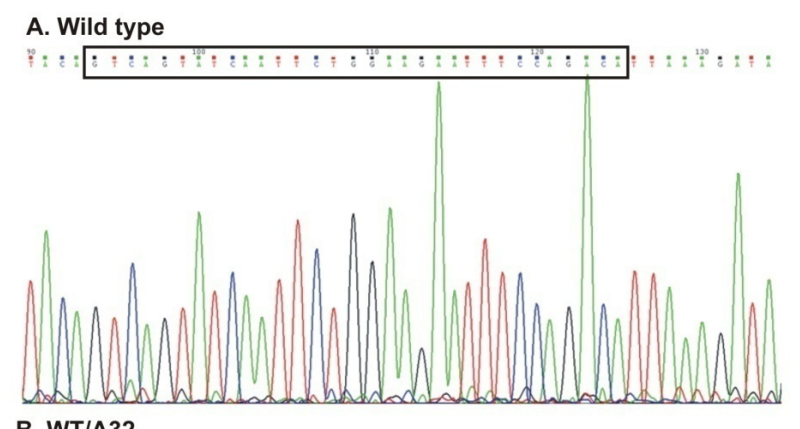

B. WT/ $\mathbf{W} 32$

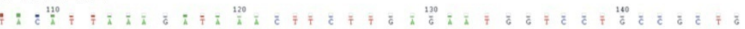

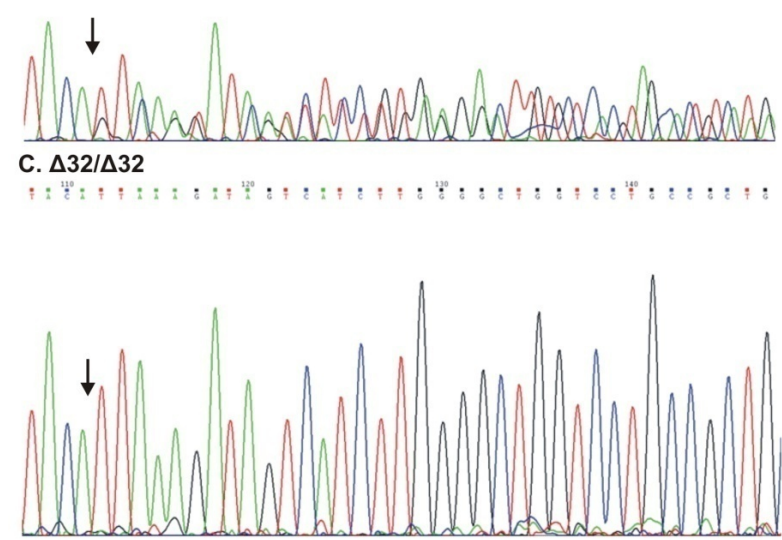

Figure 2. A Part of Electropherogram Showing WT/ WT (A), WT/ $\Delta 32$ (B) and $\Delta 32 / \Delta 32$ Genotype (C) of CCR5 $\Delta 32$ Polymorphism 


\section{Data analysis}

The data was analyzed using SPSS (Version 16, SPSS Inc, Chicago, IL). Differences in genotypic and allele frequencies of CCR5 $\triangle 32$ variant between patients and controls were evaluated by gene count and $\chi^{2}$ test. Odds ratio $(\mathrm{OR})$ with confidence interval $(\mathrm{CI})$ was also calculated. A cut off values for $\mathrm{p} \leq 0.05$ were considered statistically significant.

\section{Results}

In this case control study, 175 clinically confirmed sporadic esophageal cancer patients (69 males and 106 females) and 175 unrelated healthy control individuals (69 males and 106 females) were analyzed. The mean ages of patients and controls were 56.22 \pm 13.26 and $56.0 \pm 13.0$ years respectively. Higher incidence of EC was observed among females $(60.57 \%)$ as compared to males $(39.43 \%)$. The selected characteristics of the cases and controls are presented in Table 1 . The frequencies of wild type homozygous (CCR5/CCR5), heterozygous (CCR5/ $\Delta 32)$ and homozygous mutant $(\Delta 32 / \Delta 32)$ genotypes were $96.0 v s 97.72 \%, 4.0$ vs $1.71 \%$ and 0 vs $0.57 \%$ in patients and controls respectively (Table 2). CCR5/ $\triangle 32$ genotype

Table 1. Baseline Characteristics of Esophageal Cancer Patients and Controls

\begin{tabular}{llcc}
\hline Characteristics & & $\begin{array}{c}\text { Patients } \\
\mathrm{n}(\%)\end{array}$ & $\begin{array}{c}\text { Controls } \\
\mathrm{n}(\%)\end{array}$ \\
\hline No. of subjects & & 175 & 175 \\
Gender & Males & $69(39.43)$ & $69(39.43)$ \\
& Females & $106(60.57)$ & $106(60.57)$ \\
Age in Years & Mean \pm SD & $56.22 \pm 13.26$ & $56 \pm 13.0$ \\
& Range & $24-84$ & $24-84$ \\
Habitat & Rural & $138(78.86)$ & $138(78.86)$ \\
& Suburban & $7(4.0)$ & $7(4.0)$ \\
Habits & Urban & $30(17.14)$ & $30(17.14)$ \\
& Vegetarian & $104(59.43)$ & $94(53.71)$ \\
& Non vegetarian & $71(40.57)$ & $81(46.29)$ \\
& Smoker & $14(8.0)$ & $32(18.29)$ \\
Histology & Alcoholic & $42(24.0)$ & $6(3.43)$ \\
& Adenocarcinoma & $11(6.29)$ & - \\
& Squamous Cell & $164(93.71)$ & - \\
Clinical Stage & Carcinoma & & \\
& I & $12(6.86)$ & \\
& II & $116(66.29)$ & \\
& III & $37(21.14)$ & \\
& IV & $10(5.71)$ & \\
\hline
\end{tabular}

Table 2. Distribution of CCR5 $\Delta 32$ Genotypes and Allele in Esophageal Cancer Patients and Controls

\begin{tabular}{|c|c|c|c|c|}
\hline & $\begin{array}{c}\text { Patients } \\
\mathrm{n}(\%)\end{array}$ & $\begin{array}{c}\text { Controls } \\
\mathrm{n}(\%)\end{array}$ & OR $(95 \% \mathrm{CI})$ & $\mathrm{p}$ value \\
\hline \multicolumn{5}{|l|}{ Genotypes } \\
\hline WT/WT & $168(96.0)$ & $171(97.72)$ & Reference & \\
\hline $\mathrm{WT} / \Delta 32$ & $7(4.0)$ & 3 (1.71) & $2.37(0.60-9.34)$ & 0.204 \\
\hline$\Delta 32 / \Delta 32$ & - & $1 \quad(0.57)$ & - & \\
\hline \multicolumn{5}{|l|}{ Alleles } \\
\hline WT & $343(98.0)$ & 345 (98.57) & Reference & \\
\hline$\Delta 32$ & $7 \quad(2.0)$ & $5 \quad(1.43)$ & $1.41(0.44-4.48)$ & 0.56 \\
\hline
\end{tabular}

$*_{n}=$ Number of subjects, Figures in parentheses represent frequency; OR=Odds Ratio; $\mathrm{CI}=$ Confidence interval frequencies were not significantly different between esophageal cancer patients and control group $(p=0.204)$.

\section{Discussion}

Chemokines belong to the family of chemotactic cytokines that are considered to be the main regulators of leukocyte trafficking under homeostatic and inflammatory conditions. They may be involved in the regulation of immune cell migration and activation, tumor angiogenesis, tumor cell proliferation and metastasis (Dias et al, 2001; Coussens and Werb, 2002; Payne and Cornelius, 2002). Genetic variations in chemokine receptor genes can affect several chemokine functions including the control of leukocyte infiltration into tumors and the initiation of primary tumor growth and survival (Ghilardi et al., 2008). It has been documented that 32 base pair deletion in the coding region of CCR5 might alter the expression or function of the protein (Sidoti et al., 2005). It has been implicated in a variety of immune-mediated diseases (Yang et al., 2004; Kaimen-Maciel et al., 2007). The molecular basis of the protective effect of CCR5 432 is poorly understood. It is still unclear, whether the CCR5 $\triangle 32$ deletion may have an effect on the expression of genes which communicate immunological responses or the protective effect of the CCR5 432 deletion is completely caused by the lack of functional CCR5.

In the present case control study, genotypes and allele frequencies of CCR5/ $\triangle 32$ polymorphism did not differ significantly between esophageal cancer patients and control individuals $(\mathrm{p}>0.05)$. Thus $\Delta 32$ was not a risk factor for esophageal cancer. Similar to our report, no correlation has been reported between CCR5 432 deletion and inflammatory bowel disease (Rector et al., 2001) and gastric cancer (Gawron et al., 2011). This was contrary to previous reports where CCR5/ 432 was reported to confer significant risk for gall bladder cancer (Srivastava et al., 2008), cervical cancer (Singh et al., 2008) and was an independent risk factor for the development of breast cancer (Degerli et al., 2005).

High frequency of CCR5 432 allele has been reported in several Caucasian populations (Lucotte, 1997; Martinson et al., 1997; Libert et al., 1998; Stephens et al., 1998). In the present study, the frequencies of CCR $5 / \Delta 32$ heterozygotes and $\Delta 32 / \Delta 32$ homozygotes were $1.71 \%$ and $0.57 \%$ in the control group even though the population has a Caucasian and Indoscythian admixture (Bhasin et al., 1992). A complete absence of $\Delta 32 / \Delta 32$ homozygotes and low frequency of CCR5/ $\triangle 32$ heterozygotes between $0-6 \%$ have previously been reported in some populations of North West India (Majumder and Dey, 2001).

It has been reported that heterozygous subjects express a lower amount of functional receptors as compared to wild type homozygotes (Benkirane et al., 1997). CCR5 disruption has been demonstrated to inhibit tumor growth in pancreatic cancer (Tan et al., 2009). Mice expressing CCR5 have showed enhanced local tumor growth and an impaired response to vaccine therapy as compared to knockout mice (van Deventer et al., 2005). Blocking the homing of cancer cells to metastatic sites is a desirable characteristic in a true antimetastatic drug (Perret 
and Crepin, 2008). CCR5 inhibition with Maraviroc or Vicriviroc reduces breast cancer cellular invasion without affecting cellular viability indicating that $C C R 5$ antagonists might be useful as adjuvant therapy for basal breast tumors with CCR5 overexpression (VelascoVelazquez et al., 2012). CCR5 inhibitors have been reported to prevent cancer cell growth in prostate cancer (Zhang et al., 2010), hepatoma cells (Sutton et al., 2007), and lung cancer (Borczuk et al., 2008). In the earlier study, we reported significant association of RP genotype of p.R72P polymorphism of TP53 with increased risk of esophageal cancer in North Indians (Kaur et al., 2014). In the present study, we did not observe any difference in the allele frequency of $\Delta 32$ allele in esophageal cancer patients and control group, CCR5 432 deletion may not be associated with risk to esophageal cancer in the studied population. Also majority of the subjects being homozygous for CCR5 wild type allele, it may be worthwhile to use antiviral drug therapy as adjuvant therapy in these patients.

\section{Acknowledgements}

We thank the patients and controls for taking part in this study. Financial support from UGC DRS-1(Ref F34/2007 SAPII) and infrastructural grant DST-FIST (SR/ FST/LSI-449/2010) is duly acknowledged. We express our gratitude to Dr. Geeta Sharma, Principal, Sri Guru Ram Das Institute of Medical Sciences and Research, Vallah, Amritsar, Punjab for providing access to patients.

\section{References}

Adeli K, Ogbonna G (1990). Rapid purification of human DNA from whole blood for potential application in clinical chemistry laboratories. Clin Chem, 36, 261-4.

Aldinucci D, Lorenzon D, Cattaruzza L, et al (2008). Expression of CCR5 receptors on Reed-Sternberg cells and Hodgkin lymphoma cell lines: involvement of CCL5/Rantes in tumor cell growth and microenvironmental interactions. Int $J$ Cancer, 122, 769-76.

Aoki MN, Da Silva do Amaral Herrera AC, Amarante MK, et al (2009). CCR5 and p53 codon 72 gene polymorphisms: implications in breast cancer development. Int J Mol Med, 23, 429-35.

Apostolakis S, Baritaki S, Krambovitis E, Spandidos DA (2005). Distribution of HIV/AIDSprotective SDF1, CCR5 and CCR2 gene variants within cretan population. J Clin Virol, 34, 310-14.

Arya M, Patel HR, Williamson M (2003). Chemokines: key players in cancer. Curr Med Res Opin, 19, 557-64.

Balistreri CR, Carruba G, Calabro M, et al (2009). CCR5 proinflammatory allele in prostate cancer risk: a pilot study in patients and centenarians from Sicily. Ann N Y Acad Sci, 1155, 289-92.

Balkwill F, Mantovani A (2001). Inflammation and cancer: back to Virchow? Lancet, 357, 539-45.

Benkirane M, Jin DY, Chun RF, Koup RA, Jeang KT (1997). Mechanism of transdominant inhibition of CCR5-mediated HIV-1 infection by CCR5 432. J Biol Chem, 272, 30603-6.

Bhasin MK, Walter H, Danker-Hopfe H (1992). The distribution of genetical, morphological and behavioral traits among the peoples of Indian region. Kamla-Raj Publishers, New Delhi.

Borczuk AC, Papanikolaou N, Toonkel RL, et al (2008). Lung adenocarcinoma invasion in TGFbetaRII-deficient cells is mediated by CCL5/RANTES. Oncogene, 27, 557-64.

Chuang JY, Yang WH, Chen HT, et al (2009). CCL5/CCR5 axis promotes the motility of human oral cancer cells. J Cell Physiol, 220, 418-26.

Coussens LM, Werb Z (2002). Inflammation and cancer. Nature, 420, 860-7.

Degerli N, Yilmaz E, Bardakci F (2005). The delta32 allele distribution of the CCR5 gene and its relationship with certain cancers in a Turkish population. Clin Biochem, 38, 248-52.

Dias S, Choy M, Rafii S (2001). The role of CXC chemokines in the regulation of tumor angiogenesis. Cancer Invest, 19, 732-8.

Duell EJ, Casella DP, Burk RD, Kelsey KT, Holly EA (2006). Inflammation, genetic polymorphisms in proinflammatory genes TNF-A, RANTES, and CCR5, and risk of pancreatic adenocarcinoma. Cancer Epidemiol Biomarkers Prev, 154, 726-31.

Erreni M, Bianchi P, Laghi L, et al (2009). Expression of chemokines and chemokine receptors in human colon cancer. Methods Enzymol, 460, 105-21.

Eskandari-Nasab E, Hashemi M, Ebrahimi M, et al (2014). Evaluation of CCL5-403 G>A and CCR5 432 gene polymorphisms in patients with breast cancer. Cancer Biomark, 14, 343-51.

Gawron AJ, Fought AJ, Lissowska J, et al (2011). Polymorphisms in chemokine and receptor genes and gastric cancer risk and survival in a high risk Polish population. Scand $J$ Gastroenterol, 46, 333-40.

Ghilardi G, Biondi ML, Turri O, et al (2008). Genetic control of chemokines in severe human internal carotid artery stenosis. Cytokine, 41, 24-8.

Guleria K, Sharma S, Manjari M, et al (2012). p.R72P, PIN3 Ins16bp Polymorphisms of TP53 and CCR5 432 in North Indian breast cancer patients. Asian Pac J Cancer Prev, 13, 3305-11.

Kaimen-Maciel DR, Reiche EM, Brum Souza DG, et al (2007). CCR5-Delta32 genetic polymorphism associated with benign clinical course and magnetic resonance imaging findings in Brazilian patients with multiple sclerosis. Int $J$ Mol Med, 20, 337-44.

Kaur S, Sambyal V, Guleria K, et al (2014). Analysis of TP53 polymorphisms in North Indian sporadic esophageal cancer patients. Asian Pac J Cancer Prev, 15, 8413-22.

Libert F, Cochaux P, Beckman G, et al (1998). The delta CCR5 mutation conferring protection against HIV-1 in Caucasian populations has a single and recent origin in northeastern Europe. Hum Mol Genet, 7, 399-406.

Lucotte G (1997). Frequencies of the CC chemokine receptor 5 D32 allele in various populations of defined racial background. Biomed Pharmocother, 51, 469-73.

Majumder PP, Dey B (2001). Absence of the HIV-1 protective Delta CCR5 allele in most ethnic populations of India. Eur J Hum Genet, 9, 794-6.

Manes S, Mira E, Colomer R, et al (2003). CCR5 expression influences the progression of human breast cancer in a p53dependent manner. J Exp Med, 198, 1381-9.

Mantovani A, Sozzani S, Locati M, Allavena P, Sica A (2002). Macrophage polarization: tumor-associated macrophages as a paradigm for polarized M2 mononuclear phagocytes. Trends Immunol, $\mathbf{2 3}, 549-55$.

Martinson JJ, Chapman NH, Rees DC, Liu YT, Clegg JB (1997). Global distribution of the CCR5 gene 32 base pair deletion. Nat Genet, 16, 100-03.

McDermott DH, Conway SE, Wang T, et al (2010). Donor and recipient chemokine receptor $C C R 5$ genotype is associated 
with survival after bone marrow transplantation. Blood, 115, 2311-8.

Muller A, Homey B, Soto H, et al (2001). Involvement of chemokine receptors in breast cancer metastasis. Nature, 410, 50-6.

Payne AS, Cornelius LA (2002). The role of chemokines in melanoma tumor growth and metastasis. J Invest Dermatol, 118, 915-22.

Perret GY, Crepin M (2008). New pharmacological strategies against metastatic spread. Fundam Clin Pharmacol, 22 465-92.

Potteaux S, Combadiere C, Esposito B, et al (2006). Role of bone marrow-derived CC-chemokine receptor 5 in the development of atherosclerosis of low-density lipoprotein receptor knockout mice. Arterioscler Thromb Vasc Biol, 26, $1858-63$.

Rector A, Vermeire S, Thoelen I, et al (2001). Analysis of the $\mathrm{CC}$ chemokine receptor 5 (CCR5) delta-32 polymorphism in inflammatory bowel disease. Hum Genet, 108, 190-3.

Seidl H, Richtig E, Tilz H, et al (2007). Profiles of chemokine receptors in melanocytic lesions: de novo expression of CXCR6 in melanoma. Hum Pathol, 38, 768-80.

Sidoti A, D'Angelo R, Rinaldi C, et al (2005). Distribution of the mutated delta 32 allele of the CCR5 gene in a Sicilian population. Int J Immunogenet, 32, 193-8.

Singh H, Sachan R, Jain M, Mittal B (2008). CCR5-Delta32 polymorphism and susceptibility to cervical cancer: association with early stage of cervical cancer. Oncol Res, 17, 87-91.

Srivastava A, Pandey SN, Choudhuri G, Mittal B (2008). CCR5 432 polymorphism: associated with gallbladder cancer susceptibility. Scand J Immunol, 67, 516-22.

Stephens JC, Reich DE, Goldstein DB, et al (1998). Dating the origin of the CCR5-Delta32 AIDS-resistance allele by the coalescence of haplotypes. Am J Hum Genet, 62, 1507-15.

Sugasawa H, Ichikura T, Tsujimoto H, et al (2008). Prognostic significance of expression of CCL5/RANTES receptors in patients with gastric cancer. J Surg Oncol, 97, 445-50.

Sutton A, Friand V, Brule-Donneger S, et al (2007). Stromal cell-derived factor-1/chemokine (C-X-C motif) ligand 12 stimulates human hepatoma cell growth, migration, and invasion. Mol Cancer Res, 5, 21-33.

Tan MC, Goedegebuure PS, Belt BA, Flaherty, et al (2009). Disruption of CCR5-dependent homing of regulatory $\mathrm{T}$ cells inhibits tumor growth in a murine model of pancreatic cancer. J Immunol, 182, 1746-55.

Tanyel CR, Cincin ZB, Gokcen-Rohlig B, et al (2013). Effects of genetic variants of $C C R 5$ chemokine receptors on oral squamous cell carcinoma. Genet Mol Res, 12, 5714-20.

van Deventer HW, O'Connor W Jr, Brickey WJ, et al (2005). C-C chemokine receptor 5 on stromal cells promotes pulmonary metastasis. Cancer Res, $\mathbf{6 5}, 3374-9$.

Veillard NR, Kwak B, Pelli G, et al (2004). Antagonism of RANTES receptors reduces atherosclerotic plaque formation in mice. Circ Res, 94, 253-61.

Velasco-Velazquez M, Jiao X, De La Fuente M, et al (2012). CCR5 Antagonist blocks metastasis of basal breast cancer cells. Cancer Res, 72, 3839-50.

von Luettichau I, Segerer S, Wechselberger A, et al (2008). A complex pattern of chemokine receptor expression is seen in osteosarcoma. BMC Cancer, $\mathbf{8}, 23$.

Weng CJ, Chien MH, Lin CW, et al (2010). Effect of CC chemokine ligand 5 and $\mathrm{CC}$ chemokine receptor 5 genes polymorphisms on the risk and clinicopathological development of oral cancer. Oral Oncol, 46, 767-72.

Wilson J, Balkwill F (2002). The role of cytokines in the epithelial cancer microenvironment. Semin Cancer Biol,
12, 113-20.

Yang X, Ahmad T, Gogus F, et al (2004). Analysis of the CC chemokine receptor 5 (CCR5) Delta32 polymorphism in Behcet's disease. Eur J Immunogenet, 31, 11-4.

Zafiropoulos A, Crikas N, Passam AM, Spandidos DA (2004). Significant involvement of CCR2-64I and CXCL12-3a in the development of sporadic breast cancer. J Med Genet, 41, 59 .

Zernecke A, Liehn EA, Gao JL, et al (2006). Deficiency in CCR5 but not CCR 1 protects against neointima formation in atherosclerosis-prone mice: involvement of IL-10. Blood, 107, 4240-3.

Zhang X, Haney KM, Richardson AC, et al (2010). Anibamine, a natural product CCR5 antagonist, as a novel lead for the development of anti-prostate cancer agents. Bioorg Med Chem Lett, 20, 4627-30.

Zheng B, Wiklund F, Gharizadeh B, et al (2006). Genetic polymorphism of chemokine receptors CCR2 and CCR5 in Swedish cervical cancer patients. Anticancer Res, 26, 3669-74. 